\title{
Polyfluorene-Polytriarylamine Block Copolymer as an Additive for Electroluminescent Devices Based on Polymer Blends
}

\author{
Mehdi Jahanfar, Ying Tan, Kousuke Tsuchiya, Takeshi Shimomura, Kenji Ogino* \\ Graduate School of Bio-Applications and Systems Engineering, \\ Tokyo University of Agriculture and Technology, Tokyo, Japan \\ Email: ${ }^{*}$ kogino@cc.tuat.ac.jp
}

Received January 11, 2013; revised February 13, 2013; accepted February 21, 2013

Copyright (C) 2013 Mehdi Jahanfar et al. This is an open access article distributed under the Creative Commons Attribution License, which permits unrestricted use, distribution, and reproduction in any medium, provided the original work is properly cited.

\begin{abstract}
Electroluminescent characteristics were investigated for the blue emitting devices fabricated with the blend systems consisting of hole transporting polytriarylamine (PTAA), electron transporting polyfluorene (PF), and a block copolymer with both segments (PF-b-PTAA) as an active layer in order to elucidate the relationship between the chemical nature and morphology of the active layer, and EL performance. The addition of PF-b-PTAA to PF homopolymer afforded the hole injecting and/or electron blocking ability to increase the efficiency. The addition to PF/PTAA blend keeping the chemical composition constant also improved the performance by controlling the morphology and/or the domain size in phase-separated films.
\end{abstract}

Keywords: Polyfluorene; Polytriarylamine; Block Copolymer; Polymer Blend; Polymer-Light Emitting Diode

\section{Introduction}

Polyfluorenes (PFs) have been attracting much attention for a blue polymeric light emitting material because of their superior properties such as highly efficient luminescence, excellent thermal stability, and good solubility in common organic solvents [1,2]. PFs often have a high ionization potential resulting in an injection barrier for holes and low electroluminescent (EL) efficiency [3]. To improve the injection and conduction of holes in PFs, triarylamine (TAA) derivatives are commonly used, which are known to be good hole conductors [4-7]. Multilayered devices with fluorene-TAA copolymers as interlayers between the conductive polymer, PEDOT:PSS and the emitting layer showed much higher performance than those without the interlayer [8]. Recently we reported a different approach utilizing block copolymers consisting of PF and polytriarylamine (PTAA) segments with lower ionization potential in order to improve the EL efficiency due to the effective hole injection and/or electron blocking $[9,10]$. Hydrophilic trioxyethylene (TEO) group was attached to the side chain of PTAA. Therefore, it is considered that PTAA segment segregate into the interface by hydrogen bonding interaction with

${ }^{*}$ Corresponding author.
PEDOT:PSS layer.

Block copolymers assemble into micro- or nano-phase separated structures with various domain shapes such as lamella, cylinder, or sphere. Exploiting nanostructures of block copolymers with appropriate designs can improve performance of applications due to allocation of functionality to each domain [11]. Besides the above mentioned reports, several block copolymers for EL applications have been reported in order to improve injection of hole and electron into the emitting layer as well as recombination of charges [12-15].

We also investigated the correlation between device performance and morphology in polymer layer by evaluation of the devices based on the polymer blend (hole and electron transporting polymers), to which various contents of block copolymer are added to control phaseseparated structure, and found that the current efficiency significantly increased with the addition of the block copolymer accompanied with the decrease of surface roughness [16]. In this paper, EL devices were fabricated based on the blend systems consisting of PTAA, PF, and a block copolymer with both segments (PF-b-PTAA), and the relationship between chemical nature and morphology of the active layer, and EL performance was elucidated. 


\section{Experimental}

\subsection{Materials}

PF, PTAA homopolymers and PF-b-PTAA block copolymers were synthesized as reported $[9,10]$. Chemical structures of these polymers are shown in Figure 1. Characteristics of utilized polymers are listed on Table 1.

\subsection{Characterization}

The performance of the EL devices based on blend systems with the device structure of ITO/PEDOT:PSS (30 $\mathrm{nm}) /$ polymer $(30 \mathrm{~nm}) / \mathrm{BCP}(50 \mathrm{~nm}) / \mathrm{LiF}(0.5 \mathrm{~nm}) / \mathrm{Al}(100$ $\mathrm{nm}$ ) was evaluated. As a hole blocking layer, 2,9-dimethyl-4,7-diphenyl-1,10-phenanthroline(bathocuproine, BCP) was used between the emission layer and cathode. EL devices were fabricated as described in a previous report [9]. Atomic force microscopic (AFM) measurements were performed on JEOL JSPM 4200 system in trapping mode (phase and topographic modes) with an MPP-11100-10 silicon probe (resonant frequency: 300 $\mathrm{kHz}$, force constant: $40 \mathrm{~N} / \mathrm{m}$ ). All thin film of polymers were spin-cast onto glass slide with a MIKASA 1H-D7 spin coater from THF solutions at $1500 \mathrm{rpm}$ for $30 \mathrm{~s}$.

\section{Results and Discussion}

\subsection{PF1/PF-PTAA1 Blend System}

A series of EL devices based on PF1/PF-PTAA1 blend system were characterized to investigate the effect of the block copolymer. Figure 2 showed current efficiency vs. current density characteristics. The EL characteristics were summarized in Table 2.

With the increase of the content of the block copolymer, the luminance (at $30 \mathrm{~mA} / \mathrm{m}^{2}$ ) and the maximum current efficiency increased, and were almost equal to those of the block only device (100 wt \%). As discussed in a previous report [10], it can be speculated that PTAA segment with hydrophilic moiety segregates at the interface between PEDOT:PSS and the active layer. Therefore, it is considered that the bipolar block copolymer effectively enhances the hole injection and electron blocking ability. It is noteworthy that blend system (77 wt\%) showed higher current efficiency in the region of high current density than block only device. In the blend film, the size of PF domain is considered to be larger compared with the block copolymer film [17].

The large domain seemed to enhance the recombinetion probability and/or improve the carrier balance especially in the high current density region. As shown in Table 3, the device with PF2/PTAA showed the worst performance due to the severe phase separation (see Figure 4). It is revealed that the utilization of the block copolymer is much favorable in order to enhance the hole

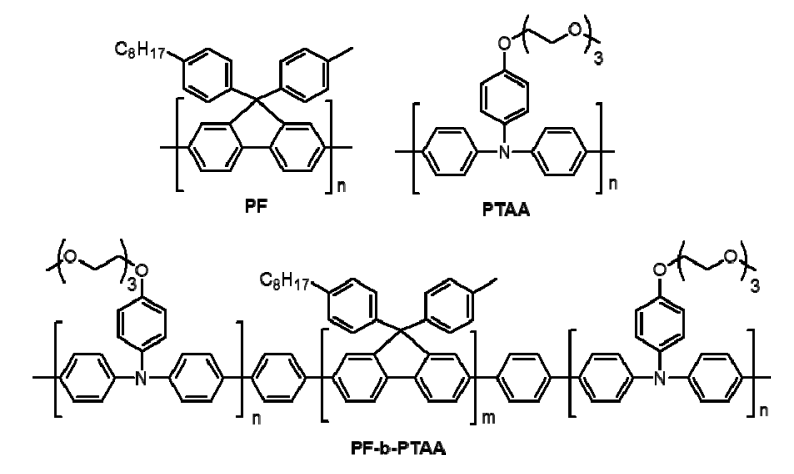

Figure 1. Chemical structure of PF, PTAA, and PF-bPTAA.

Table 1. Characteristics of utilized polymers.

\begin{tabular}{ccccc}
\hline Polymer & $\begin{array}{c}\text { Molar ratio of } \\
\text { PF/PTAA }^{\mathrm{a}}\end{array}$ & $M_{n}^{b}$ & $\mathrm{PDI}^{\mathrm{b}}$ & $T_{\mathrm{g}}{ }^{\circ} \mathrm{C}^{\mathrm{c}}$ \\
PF1 & - & 13000 & 2.4 & 118 \\
PF-b-PTAA1 & $55 / 45$ & 23000 & 2.7 & 118,174 \\
PF2 & & 26000 & 3.5 & 119 \\
PF-b-PTAA2 & $60 / 40$ & 43000 & 3.3 & 119,173 \\
PTAA & & 9700 & 2.8 & 175 \\
\hline
\end{tabular}

${ }^{\mathrm{a}}$ Determined by ${ }^{1} \mathrm{H}-\mathrm{NMR},{ }^{\mathrm{b}}$ determined by GPC, ${ }^{\mathrm{c}}$ determined by DSC.

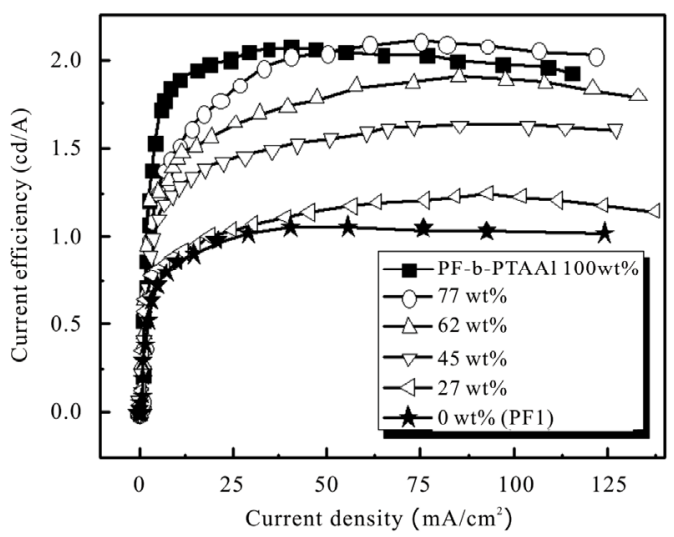

Figure 2. Current efficiency vs. current density characteristics for the devices based on PF1/PF-b-PTAA1 blend systems.

injection ability in blend systems.

\subsection{PF2/PTAA/PF-PTAA2 Blend System}

In order to investigate the effect of the morphology or domain size of phase separated systems on EL performance, we examined the ternary blend systems consisting of both homopolymers and the block copolymer keeping the chemical composition constant (fluorene:triarylamine $=60: 40$ ). The addition of corresponding block copolymer is one of the effective strategies for more stable, and finer scale morphologies [18,19]. Figure 3 showed current efficiency vs. current density characteristics for the 
Table 2. EL characteristics for the devices based on PF1/PF-b-PTAA1 blend systems.

\begin{tabular}{|c|c|c|c|}
\hline $\begin{array}{c}\text { wt\% of PF-b-PTAA1 } \\
(\%)\end{array}$ & Molar ratio of (PF/PTAA)/PF & $\begin{array}{c}\text { Luminance at } \\
\text { at } 30 \mathrm{~mA} / \mathrm{cm}^{2}\left(\mathrm{~cd} / \mathrm{m}^{2}\right)\end{array}$ & $\begin{array}{l}\text { Maximum current efficiency } \\
\text { (cd/A) }\end{array}$ \\
\hline 100 & $(55 / 45) / 0$ & 626 & $2.10(14 \mathrm{~V})$ \\
\hline 77 & $(55 / 45) / 28$ & 648 & $2.12(15 \mathrm{~V})$ \\
\hline 62 & $(55 / 45) / 55$ & 547 & $1.91(15 \mathrm{~V})$ \\
\hline 45 & $(55 / 45) / 110$ & 443 & $1.63(15.5 \mathrm{~V})$ \\
\hline 27 & $(55 / 45) / 220$ & 398 & $1.25(16 \mathrm{~V})$ \\
\hline 0 & $0 / 1$ & 297 & $1.07(13 \mathrm{~V})$ \\
\hline
\end{tabular}

Table 3. EL characteristics for the devices based on PF2/PTAA/PF-b-PTAA2 blend systems.

\begin{tabular}{|c|c|c|c|}
\hline $\begin{array}{c}\text { wt \% of PF-b-PTAA2 } \\
(\%)\end{array}$ & $\begin{array}{c}\text { Molar ratio of (PF/PTAA)/PF2/ } \\
\text { PTAA }\end{array}$ & $\begin{array}{c}\text { Luminance at } \\
\text { at } 30 \mathrm{~mA} / \mathrm{cm}^{2}\left(\mathrm{~cd} / \mathrm{m}^{2}\right)\end{array}$ & $\begin{array}{l}\text { Maximum current efficiency } \\
\text { (cd/A) }\end{array}$ \\
\hline 100 & $(60 / 40) / 0 / 0$ & 724 & $2.15(15 \mathrm{~V})$ \\
\hline 80 & $(60 / 40) / 15 / 10$ & 648 & $2.28(16.5 \mathrm{~V})$ \\
\hline 60 & $(60 / 40) / 40 / 27$ & 521 & $2.07(16 \mathrm{~V})$ \\
\hline 40 & $(60 / 40) / 90 / 60$ & 478 & $1.78(17 \mathrm{~V})$ \\
\hline 20 & $(60 / 40) / 240 / 160$ & 407 & $1.51(17 \mathrm{~V})$ \\
\hline 0 & $0 / 60 / 40$ & 235 & $0.88(14 \mathrm{~V})$ \\
\hline
\end{tabular}

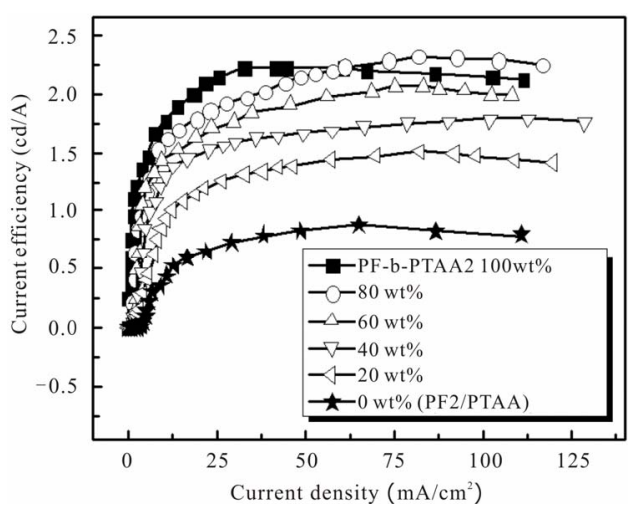

Figure 3. Current efficiency vs. current density characteristics for the devices based on PF2/PTAA/PF-b-PTAA2 blend systems.
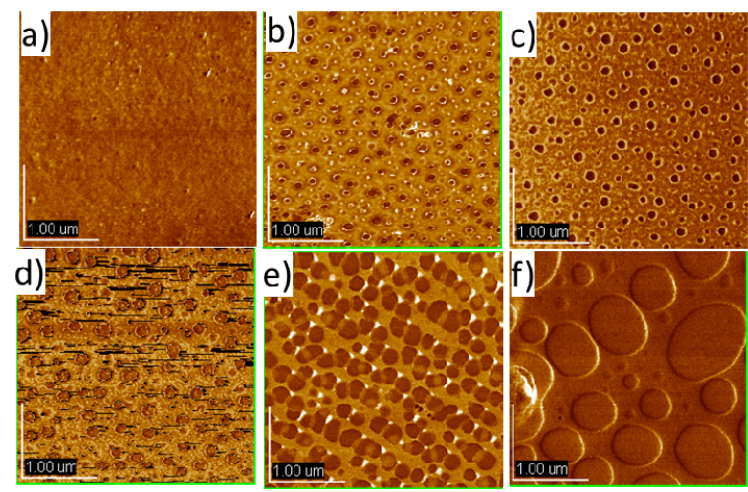

Figure 4. AFM images for PF2/PTAA/PF-b-PTAA2 blend films on PEDOT/PSS (tapping mode). PF-b-PTAA2 content is: a) $100 \mathrm{wt} \%$; b) $80 \mathrm{wt} \%$; c) $60 \mathrm{wt} \%$; d) $40 \mathrm{wt} \%$; e) 20 wt \%; and f) $0 \mathrm{wt} \%$. All thin films (ca. $30 \mathrm{~nm}$ thick) were annealed at $120^{\circ} \mathrm{C}$ for $1 \mathrm{~h}$.
PF2/PTAA/PF-b-PTAA2 blend systems. The EL characteristics were summarized in Table 3. Although it is found that the addition of PTAA component to the active layer improved the performance as shown in Fig- ure 2 and Table 2, the simple blend of both homo- polymers afforded the worst performance we examined as above mentioned.

This result strongly suggests that the morphology in the active layer also plays an important role as well as its chemical characters. In fact, the maximum current efficiency and luminescence at $30 \mathrm{~mA} / \mathrm{cm}^{2}$ increased with the increase of the content of PF-b-PTAA2. The similar effect of a block copolymer as an additive was observed for electro-phosphorescent devices based on the blend systems consisting of two types of vinyl homopolymers (hole and electron transporting), and bipolar block copolymer with both segments [16]. Figure 4 represents the AFM images of blend films with the thickness of ca. $30 \mathrm{~nm}$ on PEDOT/PSS in a tapping mode. In the simple blend (Figure 4(f)), ca. $1 \mu \mathrm{m}$ of domains were observed, and the domain size decreased as the content of PF-bPTAA2 increased. These results indicate that the finer domain size was achieved by the addition of the block copolymer as expected, and was favorable for better EL performance. Higher current efficiency was observed at the higher current density region for the blend system ( 80 $\mathrm{wt} \%$ of block copolymer) than block only device. As discussed above, this is probably due to the appropriate domain size for the effective recombination and/or carrier balance in the blend system.

The relationship between the block copolymer content and EL performance for both blend systems are shown in 
Figure 5. For both cases, the maximum current efficien cies increased with the content of the block copolymer, and reached almost constant values at $80 \mathrm{wt} \%$. The addition of block copolymers altered mainly the chemical nature of the active layer in the first blend system, and changed the morphological nature in the second system.

As shown in Figure 5, it is found that EL performance is governed by the both factors which can be controlled by the utilization of block copolymers as the additive to $\mathrm{PF}$ or PF/PTAA blend systems. Figure 6 shows EL spectra for typical two types of devices (PF1/PF-bPTAA1 77 wt $\%$, and PF2/PTAA/PF-b-PTAA $80 \mathrm{wt} \%$ ). These profiles are almost the same as that observed for the block copolymer based device [6]. Other devices also exhibited a similar blue EL profiles without unnecessary green-emitting bands.

\section{Conclusion}

We demonstrated the method how to improve the EL performance of blue-emitting devices based on polymer

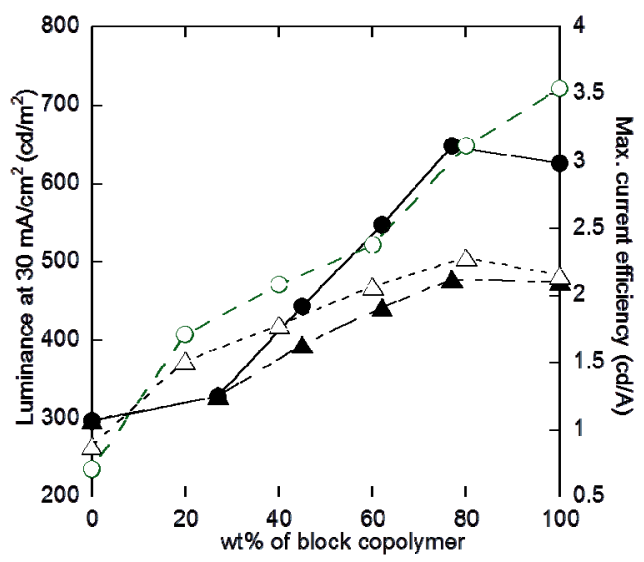

Figure 5. Relationship between the content of block copolymer and EL performance. Filled and open symbols are for the devices based on PF1/PF-b-PTAA1, and PF2/PTAA/ PF-b-PTAA2 blend systems, respectively. Circle and traingle represent luminescent at $30 \mathrm{~mA} / \mathrm{cm}^{2}$ and maximum current efficiency, respectively.

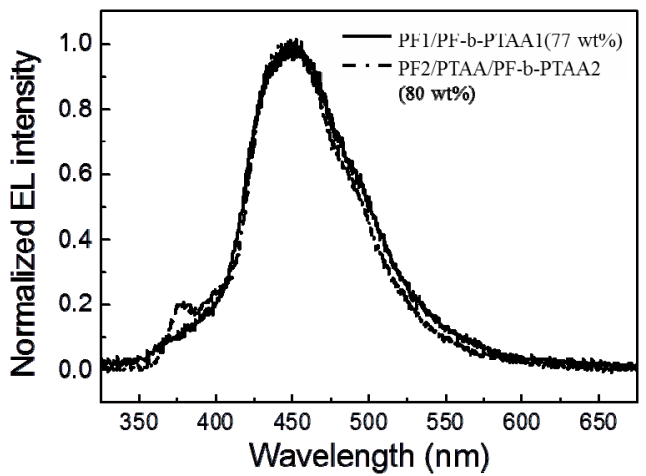

Figure 6. Electroluminescence spectra for devices based on both blend systems at $14 \mathrm{~V}$. blends. PF-b-PTAA block copolymer afforded hole injecting and/or electron blocking ability to $\mathrm{PF}$, and it worked as a compatibilizer for PF/PTAA blend to control the morphology of blend films. In order to optimize morphology and EL performance, further studies are underway including the investigation of the effect of the molecular weights on both homopolymers and block copolymer, and the chemical composition of the latter.

\section{REFERENCES}

[1] Y. Ohmori, M. Uchida, K. Muro and K. Yoshino, "Blue Electroluminescent Diodes Utilizing Poly (Alkylfluorene)," Japanese Journal of Applied Physics, Vol. 30, No. 11B, 1991, pp. 1941-1943. doi:10.1143/JJAP.30.L1941

[2] M. Leclerk, "Polyfluorenes: Twenty Years of Progress," Journal of Polymer Science Part A: Polymer Chemistry, Vol. 39, No. 17, 2001, pp. 2867-2873. doi:10.1002/pola.1266

[3] S. K. Lee, T. Ahn and N. S. Cho, "Synthesis of New Polyfluorene Copolymers with a Comonomer Containing Triphenylamine Units and Their Applications in WhiteLight-Emitting Diodes," Journal of Polymer Science Part A: Polymer Chemistry, Vol. 45, No. 7, 2007, 45, pp. 1199-1209.

[4] M. Redecker, D. D. Bradley, M. Inbasekaran, W. W. Wu and E. P. Woo, "High Mobility Hole Transport FluoreneTriarylamine Copolymers," Advanced Materials, Vol. 11, No. 3, 1999, pp. 241-246. doi:10.1002/(SICI)1521-4095(199903)11:3<241::AID-A DMA241>3.0.CO;2-J

[5] C. Ego, A. Grimsdale, F. Uckert, G. Yu, G. Srdanov and K. Müllen, "Triphenylamine-Substituted PolyfluoreneA Stable Blue-Emitter with Improved Charge Injection for Light-Emitting Diodes," Advanced Materials, Vol. 14, No. 11, 2002, pp. 809-811.

doi:10.1002/1521-4095(20020605)14:11<809::AID-AD MA809>3.0.CO;2-8

[6] T. Miteva, A. Meisel, W. Knoll, H. G. Nothofer, U. Scherf, D. C. Müller, K. Meerholz, A. Yasuda and D. Neher, "Improving the Performance of Polyfluorene-Based Organic Light-Emitting Diodes via End-capping," Advanced Materials, Vol. 13, No. 8, 2001, pp. 565-570. doi:10.1002/1521-4095(200104)13:8<565::AID-ADMA5 $65>3.0 . \mathrm{CO} ; 2-\mathrm{W}$

[7] H. T. Nicolai, A. Hof, J. L. M. Oosthoek and P. W. M. Blom, "Charge Transport and Recombination in Polyspirobifluorene Blue Light-Emitting Diodes," Advanced Functional Materials, Vol. 21, No. 8, 2011, pp. 15051510. doi:10.1002/adfm.201002293

[8] L. Duan, B. D. Chin, N. C. Yang, M.-H. Kim, H. D. Kim, S. T. Lee and H. K. Chung, "Multilayer Blue Polymer Light-Emitting Devices with Spin-Coated Interlayers," Synthetic Metals, Vol. 157, No. 8-9, 2007, pp. 343-346. doi:10.1016/j.synthmet.2007.03.011

[9] Y. Tan, Z. Gu, K. Tsuchiya and K. Ogino, "Synthesis and Luminescent Properties of Block Copolymers Based on Polyfluorene and Polytriphenylamine," Polymer, Vol. 53, 
No. 7, 2012, pp. 1444-1452.

[10] Y. Tan, K. Tsuchiya and K. Ogino, "Synthesis of Polyfluorene Block Copolymers and Effect of Side Chain Group on Electroluminescent Device Performance," Chemistry Letters, Vol. 41, No. 3, 2012, pp. 257-259. doi:10.1246/cl.2012.257

[11] C. Park, J. Yoon and E. L. Thomas, "Enabling Nano-technology with Self Assembled Block Copolymer Patterns," Polymer, Vol. 44, No. 22, 2003, pp. 6725-6760. doi:10.1016/j.polymer.2003.08.011

[12] L. Deng, P. T. Furuta, S. Garon, J. Li, D. Kavulak, M. E. Thompson and J. M. J. Fréchet, "Living Radical Polymerization of Bipolar Transport Materials for Highly Efficient Light Emitting Diodes," Chemistry of Materials, Vol. 18, No. 2, 2006, pp. 386-395. doi:10.1021/cm051922+

[13] B. Ma, B. J. Kim, L. Deng, D. A. Poulsen, M. E. Thompson and J. M. J. Fréchet, "Bipolar Copolymers as Host for Electroluminescent Devices: Effects of Molecular Structure on Film Morphology and Device Performance," Macromolecules, Vol. 40, No. 23, 2007, pp. 8156-8161. doi: $10.1021 / \mathrm{ma} 0715526$

[14] K. Tsuchiya, K. Sakaguchi, H. Kasuga, A. Kawakami, H. Taka, H. Kita and K. Ogino, "Synthesis of Charge Transporting Block Copolymers Containing 2,7-Dimethoxycarbazole Units for Light Emitting Device," Polymer, Vol. 50, No. 3, 2010, pp. 616-622. doi:10.1016/j.polymer.2009.12.024
[15] K. Tsuchiya, H. Kasuga, A. Kawakami, H. Taka, H. Kita and K. Ogino, "Synthesis of Bipolar Charge Transporting Block Copolymers and Characterization for Organic Light-Emitting Diode," Journal of Polymer Science Part A: Polymer Chemistry, Vol. 48, No. 7, 2010, pp. 1461-1468. doi:10.1002/pola.23853

[16] K. Tsuchiya, K. Sakaguchi, A. Kawakami, H. Taka, H. Kita, T. Shimomura and K. Ogino, "Charge Transporting Block Copolymer for Morphological Control in Light Emitting Device Based on Polymer Blends," Synthetic Metals, Vol. 160, No. 15-16, 2010, pp. 1679-1682. doi:10.1016/j.synthmet.2010.05.040

[17] D. J. Kinning, E. L. Thomas and L. J. Fetters, "Morphological Studies of Micelle Formation in Block Copolymer/Homopolymer Blends," Journal of Chemical Physics, Vol. 90, No. 10, 1989, pp. 5806-5825. doi: $10.1063 / 1.456388$

[18] C. Koning, M. V. Duin, C. Pagnoulle and R. Jerome, "Strategies for Compatibilization of Polymer Blends," Progress in Polymer Science, Vol. 23, No. 4, 1998, pp. 707-757. doi:10.1016/S0079-6700(97)00054-3

[19] J. A. Gallowaya, H. K. Jeonb, J. R. Bell and C. W. Macosko, "Block Copolymer Compatibilization of Cocontinuous Polymer Blends," Polymer, Vol. 46, No. 1, 2005, pp. 183-181. doi:10.1016/j.polymer.2004.10.061 